\title{
Measuring long-term strains in concrete by microcomputer*
}

\author{
M. J. S. Hirst \\ Contribution by J. J. A. Tolloczko† and P. J. Wainwright $\ddagger$ \\ $\dagger$ Wimpey Offshore Limited, $\ddagger$ University of Leeds
}

Dr Hirst's use of a Commodore Pet to activate and log data from acoustic strain gauges has also been found by ourselves to be a very satisfactory method of measuring and storing short- and long-term strain data. Not only does the computer provide a versatile data-logging facility, but also the gauges have proved to be efficient and stable during long-term and elevated temperature-strain measurements. We would, however, emphasize the need to incorporate a facility for measuring the temperature of the gauge as well as its surrounding environments.

Strain, as measured by the acoustic gauge, is a function of the frequency of oscillation of the wire. For a constant temperature, this frequency is directly related to the strain of the concrete. However, changes in temperature will cause the wire to expand or contract and hence affect the frequency as measured. This temperature effect is particularly important when considering thermal movement of concrete, as the measured frequency of the gauge will give a resultant strain and not the true strain of the concrete. Equations 1 and 2 give the relationship between true, resultant and gauge-wire temperature strains:

\section{Reply by the author}

Mr Tolloczko and Dr Wainwright are correct in pointing to the difficulties of interpreting strains measured with acoustic gauges when there are also changes in environmental temperature. The situation is even more complex if the free thermal strains estimated from the coefficient of thermal expansion are partially restrained by the surrounding structure.

As I reported in the original paper, the system was developed for a research programme into the thermal

\footnotetext{
*Pages 175 to 178 of $M C R 124$.
}

$\varepsilon_{\mathrm{r}}=\varepsilon_{\mathrm{c}}-\varepsilon_{\mathrm{GW}} \ldots \ldots \ldots \ldots \ldots \ldots \ldots \ldots \ldots \ldots \ldots \ldots$
$\varepsilon_{\mathrm{c}}=\varepsilon_{\mathrm{r}}+\varepsilon_{\mathrm{GW}}$

where $\varepsilon_{\mathrm{r}}=$ resultant strain as measured by the gauge;

$\varepsilon_{\mathrm{c}} \quad=$ true strain of the concrete;

$\varepsilon_{\mathrm{GW}}=$ strain of gauge wire due to its expansion or contraction $=$ coefficient of thermal expansion of wire $\left(\alpha_{\mathrm{GW}}\right) \times$ temperature change $(\Delta \theta)$.

A typical value of $a_{\mathrm{GW}}$ is quoted in sales literature as 11 microstrain per degree $\mathrm{C}$, so for a seasonal temperature variation of $30^{\circ} \mathrm{C}$ the resultant strain could be in error by approximately 330 microstrain.

By linking the facility for temperature-logging directly to the micro-computer and incorporating equation 2 in the software, true concrete strains can be calculated and directly logged. Subsequent corrections to the resultant strains are hence eliminated and therefore the automatic logging and numerical computation capacity of the microcomputer are fully utilized.

loading of concrete roofs heated by solar radiation. Part of this programme involves a study of the behaviour of actual roofs using the computer to record incident roof temperatures as well as concrete strains. As an illustration of the problem of interpreting concrete strains, I now include some of the results from this study.

Figure I shows the daily variation of temperature and strain measured in the top deck of a parking garage located in Adelaide, Australia. The top deck is a $140 \mathrm{~mm}$ post-tensioned slab plus $25 \mathrm{~mm}$ of screed 


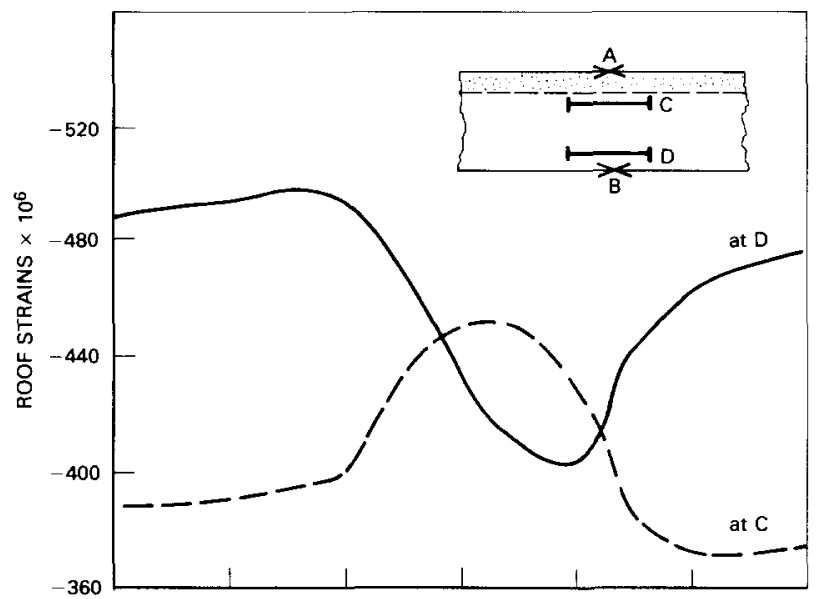

daylight

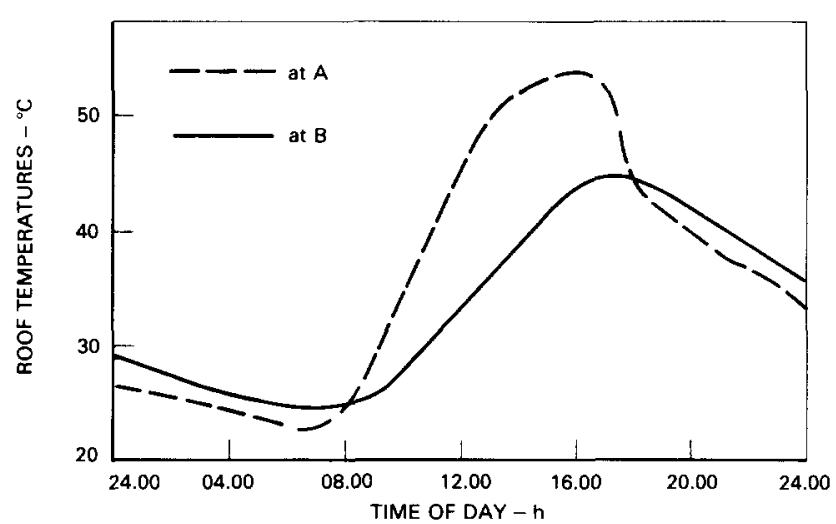

Figure I: Variations during the $24 \mathrm{~h}$ of a hot summers' day (16 February 1984) in the recorded temperature at the top and bottom of the post-tensioned top deck of a parking garage in Adelaide, and of the strains measured by the upper and lower acoustic strain gauges installed in the slab at the time of construction. with all instrumentation installed at the time of casting.

During the morning, as the top of the slab warms up relative to the soffit, the acoustic strain gauge at the top shows an increase in compressive strain and the gauge at the bottom a decrease: the exact reverse of what you would expect considering free thermal strain. The explanation of this apparently contradictory behaviour can be found in the nature of the acoustic strain gauge itself. The gauges automatically compensate for the free thermal strain of steel. Hence, under thermal loading, assuming the coefficients of expansion of steel and concrete are equal, the gauges will only indicate a strain if the structure is restrained. Then they record the difference between the actual strain and the free thermal strain. In the car park, the slab is restrained by its supporting structure from free thermal hogging so, as its top warms up, the top strain gauge records an increase in compression, i.e. the difference between the free thermal strain and the actual permitted strain.

The same care must also be used when calculating the thermal coefficient of expansion for the slab. During the day there are two periods without bending: at noon when the average temperature is $36 \cdot 6^{\circ} \mathrm{C}$ and at $17.00 \mathrm{~h}$ when the average temperature is $47 \cdot 8^{\circ} \mathrm{C}$. The corresponding average slab strains are $-450 \times 10^{-6}$ and $-415 \times 10^{-6}$ respectively. A simple calculation gives an apparent coefficient of thermal expansion of $3.1 \times 10^{-6} /{ }^{\circ} \mathrm{C}$. However, given the nature of the strain gauges, the coefficient of thermal expansion of steel must be added to the apparent value to give a true value of $14 \cdot 1 \times 10^{-6} /{ }^{\circ} \mathrm{C}$ for the coefficient of thermal expansion of the prestressed slab. 